\title{
Medicine-related services in community pharmacy: public preferences for pharmacy attributes and promotional methods and comparison with pharmacists' perceptions
}

\author{
This article was published in the following Dove Press journal: \\ Patient Preference and Adherence \\ 7 November 2016 \\ Number of times this article has been viewed
}

\section{Shivaun M Gammie \\ Ruth M Rodgers \\ Ruey Leng Loo \\ Sarah A Corlett \\ Janet Krska}

Medway School of Pharmacy, The Universities of Greenwich and Kent, Chatham Maritime, Kent, UK
Correspondence: Janet Krska Medway School of Pharmacy, The

Universities of Greenwich and Kent, Chatham Maritime, Kent ME4 4TB, UK

Tel +44 1634202950

Fax +441634883827

Email j.krska@kent.ac.uk
Background: Public awareness of pharmacy services designed to support the use of medicines is low, yet little is known about how the public view promotion of these services, or their preferences for the attributes of pharmacies from which they would like to receive them.

Objective: To compare the public's preferred attributes of pharmacies and methods for promoting medicine-related services with community pharmacists' perceptions of their customers' views.

Methods: Parallel surveys were conducted in South East England, using a street survey for the general public and a postal survey for community pharmacists.

Results: Response rates were as follows: public 47.2\% (1,000/2,012) and pharmacists $40.8 \%$ (341/836). Pharmacists' perceptions of customer preferences for using the same pharmacy, independent ownership, and personal knowledge of the pharmacist were higher than actual public preferences. More pharmacists than public respondents also believed that approachability and previous good service would be important. The public's desires for long opening hours and for a pharmacy with a good relationship with their doctor's surgery were higher than pharmacists believed. The majority of the public prefer not to interrupt a pharmacist who is busy in the dispensary, which was not perceived by pharmacists as a factor. Pharmacists' perceptions aligned more with the preferences of regular medicine users and frequent pharmacy users. Both groups viewed direct recommendation as the most effective approach for promoting pharmacy services, particularly by doctors and pharmacy staff. Pharmacists' expectations of the effectiveness of posters and mass media methods were much higher than those of the public.

Conclusion: Pharmacists and pharmacy owners must ensure good relationships with local medical practices to enable them to maximize opportunities for using the promotional methods judged most effective in encouraging the use of medicine-related services. Staff must be approachable and enable access to pharmacists, ensuring that perceptions of pharmacist busyness are not a deterrent

Keywords: community pharmacy, public preferences, pharmacist views, promotion of services, pharmacy attributes, medicine-related services

\section{Introduction}

Community pharmacists provide information and advice about medicines they dispense or sell to the public and increasingly provide additional cognitive services to support and improve the use of medicines, either funded by government or third-party payers. Examples of these are the home medicine review (HMR) service in Australia, medication 
therapy management services (MTM) in the US, and the medicines use review (MUR) and new medicines service (NMS) in England. While research has investigated the provision of these services from the perspectives of both pharmacists and users separately, relatively few studies have compared the views of pharmacists and potential service users. ${ }^{1-3}$ Studies in the US have explored the expectations of potential users of MTM and investigated the factors they view as important in selecting a pharmacy., ${ }^{4,5}$ Consumers' and carers' views on preferences for new pharmacy services have also recently been explored in Australia. ${ }^{6-8}$ However, no similar work exists in England, where studies instead concentrate on determining the actual use of pharmacies with different attributes and the services they provide, rather than the reasons for use. ${ }^{9-11}$

What is known is that public awareness of medicine-related services is low, in both England ${ }^{12,13}$ and elsewhere. ${ }^{5,14,15}$ Most people prefer to seek advice about medicines from their family doctor, rather than a pharmacist. ${ }^{11}$ In the UK, the Royal Pharmaceutical Society has highlighted the need for greater public awareness of pharmacy services designed to support the use of medicines. ${ }^{16}$ Increasing the awareness to improve public demand for services such as these may be required, but relatively little work has explored how this should be achieved.

Leaflets describing services are a common method advocated by professional organizations, and national templates for such leaflets are available. ${ }^{14,16}$ The leaflet describing the Australian HMR service was however viewed by researchers as not explaining adequately how problems with medicines may occur and the role of the pharmacist in identifying and helping to resolve these. ${ }^{14}$ Meanwhile, a study investigating the language used in leaflets promoting the English MUR service found that they portrayed the MUR as a "traditional pattern of patient-professional relationship with the pharmacist now in charge of educating the patient". ${ }^{17}$ No work has explored whether leaflets are however the best method of promoting these services in England, although in the US, a small study involving 163 people using eight pharmacies found that preferences for promoting pharmacy services were weekly grocery store ads (68.6\%), in-store signs (51\%), and flyers attached to prescription bags $(36 \%) .{ }^{18}$ Other US studies suggest that marketing approaches involving personal contact, such as relationship marketing, are most useful, because patients need to understand the service and experience it to derive benefit and hence appreciate the service's value. ${ }^{19}$ This approach, as opposed to mass media campaigns, selects patients with similar needs and promotes new services to those perceiving benefit from existing services. However, a study comparing methods of promoting these services found no differences between active (face-to-face offers and telephone calls) or passive approaches (letters and bag stuffers) in service uptake. ${ }^{20}$

The perceptions of English community pharmacists on public or consumer preferences for pharmacies and promotion of their services have also not been sought. Nor have any studies in England compared the views of pharmacists with those of the public whom they serve. This study therefore aimed to obtain the views of English community pharmacists on their perceptions regarding public preferences for pharmacy attributes and promotional methods and the actual preferences of the public and to compare the views of both groups.

\section{Methods}

Two surveys were conducted between September and December 2012, one involving the general public and the other the community pharmacists. Study approval was obtained from Medway School of Pharmacy Research Ethics Committee (reference numbers: 010912 and 020912). Written information was provided to all potential participants indicating that questionnaire responses were anonymous. Members of the public provided verbal consent and the pharmacist questionnaire contained a statement that consent was implied by its return.

\section{Questionnaire development, piloting, and distribution}

\section{Public questionnaire}

A previously validated questionnaire used to obtain public views on pharmacy public health services ${ }^{21}$ was adapted for this study using findings from a focus group involving members of the public, which sought views on medicinerelated services (Supplementary material). ${ }^{12}$ The questionnaire included a series of statements describing attributes of pharmacies, staff, and practices, with which respondents were asked to indicate agreement (using the options agree, don't mind, and disagree). A list of potential promotional methods for medicine-related cognitive services was provided, with which respondents were asked to indicate the likelihood of each encouraging them to access these services (using the options yes, maybe, and no). Demographic data included the following: gender, age, ethnicity, educational level, and postcode for the assessment of deprivation status. Open questions allowed respondents to indicate any additional preferences for pharmacy attributes and promotional methods.

\section{Pharmacist questionnaire}

This was designed to overlap with the public questionnaire, enabling comparisons to be made, covering pharmacists' 
opinions on peoples' preferences for the same attributes and their views on whether the same promotional methods would encourage uptake (Supplementary material). Demographic details gathered included the following: gender, years qualified, role in pharmacy, pharmacy type, and location. Open questions were used to elicit additional views, perceived public preferences for pharmacy attributes, and effective promotional methods.

\section{Piloting}

This involved 25 members of the public and five pharmacists known to the research team. Both groups were asked to complete the respective questionnaires and provide comments on its relevance, suitability for purpose, and ease of use. This resulted in minor amendments to both questionnaires.

\section{Distribution}

The public survey was conducted using interviewer-assisted completion, face to face with members of the public, recruited at high street locations in ten towns across the county of Kent, noting the number who declined. Interviews were carried out by ten students trained to ensure a consistent approach. Quota sampling was used, with a target of 100 respondents per town, to ensure that, as far as possible, respondents were representative of the county in terms of gender and age. Passers-by were approached by a researcher and invited to participate. Initial screening questions excluded people under 18 years of age and qualified or trained health care professionals.

The pharmacist questionnaire was sent by post to all 836 community pharmacies in Kent, Surrey, and Sussex, followed by a second mailing and telephone call to nonresponders.

\section{Data analysis}

Data were analyzed using SPSS v22 (IBM Corporation, Armonk, NY, USA). The use of regular medicines by the public was dichotomized into any or none, and frequency of pharmacy use was dichotomized into frequent (at least once per month) or infrequent (less than once a month/never) to facilitate analysis. Spearman's correlation was used to assess the relationship between regular medicines use and frequency of pharmacy use. Chi-squared tests were used to assess differences in the proportions of the public and pharmacists agreeing to statements covering the same attributes and to evaluate the effect of both regular medicines and frequency of pharmacy use on public views. Missing data were excluded from the analysis. Public preferences for promotional methods were dichotomized into yes and no/ maybe, to facilitate binary logistic regression analysis, which included variables found to have an influence on preferences for promotional methods. Due to the large number of comparisons made, a $P$-value of $<0.001$ was used to indicate statistically significant differences between pharmacist and public responses. Free-text responses to open questions were categorized and quantified.

\section{Results}

\section{Response rates and demographic details}

Response rates were $47.2 \%$ for the public survey and $40.8 \%$ for the pharmacist survey. Demographic characteristics of both groups are shown in Table 1. The quota sampling

Table I Demographic characteristics of public and pharmacist respondents

\begin{tabular}{|c|c|}
\hline Public respondents & Number (\%) \\
\hline \multicolumn{2}{|l|}{ Gender (n=999) } \\
\hline Female & $526(52.7)$ \\
\hline Male & $473(47.3)$ \\
\hline \multicolumn{2}{|l|}{ Age group (years; $n=1,000$ ) } \\
\hline$<34$ & $280(28.0)$ \\
\hline $35-64$ & $502(50.2)$ \\
\hline 65 and older & $218(21.8)$ \\
\hline \multicolumn{2}{|l|}{ Ethnicity $(n=985)$} \\
\hline White & $712(72.3)$ \\
\hline Other ethnicities & $273(27.7)$ \\
\hline \multicolumn{2}{|l|}{ Deprivation status ( $\mathrm{n}=920$ ) } \\
\hline I (highest) & $157(17.1)$ \\
\hline 2 & $166(18.0)$ \\
\hline 3 & $172(18.7)$ \\
\hline 4 & $223(24.2)$ \\
\hline 5 (lowest) & $202(22.0)$ \\
\hline \multicolumn{2}{|l|}{ Educational level $(n=992)$} \\
\hline None/primary/secondary & $3 \mid 4(3 \mid .7)$ \\
\hline Further education & $359(36.2)$ \\
\hline Bachelor/higher degree & $319(32.2)$ \\
\hline \multicolumn{2}{|c|}{ Use of prescribed medicines $(n=1,000)$} \\
\hline None & $395(39.5)$ \\
\hline$\leq 4$ & $376(37.6)$ \\
\hline $5-8$ & $172(17.2)$ \\
\hline$>8$ & $57(5.7)$ \\
\hline \multicolumn{2}{|l|}{ Use of pharmacies ( $n=999$ ) } \\
\hline More than once a month & $136(13.6)$ \\
\hline Once a month & $373(37.3)$ \\
\hline Once every $2 / 3$ months & $258(25.8)$ \\
\hline Less than every 3 months & $91(9.1)$ \\
\hline Never use/do not know & $14 \mid(\mid 4.1)$ \\
\hline Pharmacist respondents & Number (\%) \\
\hline \multicolumn{2}{|l|}{ Gender $(n=338)$} \\
\hline Female & $179(53.0)$ \\
\hline Male & $159(47.0)$ \\
\hline \multicolumn{2}{|l|}{ Role in pharmacy $(n=340)$} \\
\hline Manager/sole pharmacist & $269(79.1)$ \\
\hline Second pharmacist & $22(6.5)$ \\
\hline Locum & $36(10.6)$ \\
\hline Superintendent & $13(3.8)$ \\
\hline \multicolumn{2}{|l|}{ Type of pharmacy $(n=340)$} \\
\hline Large chain ( $\geq 31$ pharmacies) & $223(65.6)$ \\
\hline Medium chain $(1 \mathrm{I}-30)$ & $19(5.6)$ \\
\hline Small chain $(2-10)$ & $33(9.7)$ \\
\hline Single pharmacy & $65(19.1)$ \\
\hline
\end{tabular}


ensured representativeness of public respondents in terms of age, gender, and deprivation status, and the pharmacist respondents were similar to national data in terms of pharmacy ownership, role, and years qualified. ${ }^{22}$

Approximately half of the public respondents $(509 ; 50.9 \%)$ used a pharmacy at least once a month and 605 (60.5\%) used regular prescription medicines. The number of medicines used was positively associated with higher frequency of pharmacy use (Spearman's $r=0.352 ; P<0.001$ ); however, there were 85 people ( $8.5 \%$ ) who indicated frequent use of a pharmacy but were not regular users of medicines. Conversely, 180 (18\%) regular medicine users used a pharmacy less than once every 2 months. There were 248 (24.9\%) who claimed they had experienced a review of all their medicines in a private room (MUR) and 194 (19.4\%) who recalled receiving advice about a new medicine in a private room (NMS). Of the pharmacists who completed questions relating to MUR and NMS provision, 95\% (284/299) indicated they had provided at least one MUR and 82.2\% (254/309) at least one NMS in the previous month.

\section{Public preferences for attributes of pharmacies, staff, and practices}

Overall, the strongest preferences expressed were for pharmacies being located near to home $(83.7 \%)$ or the doctor's surgery (79.9\%); regarding staff characteristics, pharmacists appearing approachable (87.4\%), and previously helpful staff (83.1\%); and regarding practices, staff who make it easy to speak to the pharmacist (81.6\%; Table 2). However, a high proportion of the public also expressed a

Table 2 Agreement with desirability of different attributes of pharmacies, staff, and practices expressed by the public and community pharmacists

\begin{tabular}{|c|c|c|c|c|c|c|c|}
\hline \multirow[t]{3}{*}{ Pharmacy attribute } & \multicolumn{6}{|c|}{ Proportion of respondents } & \multirow{3}{*}{$\begin{array}{l}P \text {-value (chi- } \\
\text { squared test) }\end{array}$} \\
\hline & \multicolumn{3}{|c|}{$\begin{array}{l}\text { Public preferences } \\
(\mathrm{n}=1,000)\end{array}$} & \multicolumn{3}{|c|}{$\begin{array}{l}\text { Pharmacist perceptions } \\
(n=34 I)\end{array}$} & \\
\hline & Agree & $\begin{array}{l}\text { Do not } \\
\text { mind }\end{array}$ & Disagree & Agree & $\begin{array}{l}\text { Do not } \\
\text { mind }\end{array}$ & Disagree & \\
\hline \multicolumn{8}{|l|}{ Pharmacy characteristics } \\
\hline Prefer to use same pharmacy every time & 66.4 & 29.3 & 4.2 & 87.7 & 9.8 & 1.5 & $<0.001$ \\
\hline Prefer a pharmacy owned by large company & 33.2 & 45.3 & 21.4 & 9.5 & 53.1 & 37.4 & $<0.001$ \\
\hline Prefer a pharmacy owned by a pharmacist working there & 26.6 & 56.5 & 16.8 & 22.6 & 50.9 & 26.2 & 0.002 \\
\hline Prefer a pharmacy in a supermarket & 20.6 & 40.4 & 38.9 & 3.9 & 47.5 & 48.7 & $<0.001$ \\
\hline Prefer a pharmacy near where I/they live & 83.7 & 11.4 & 4.8 & 95.3 & 3.3 & 1.5 & $<0.001$ \\
\hline Prefer a pharmacy near work & 57.4 & 28.2 & 14.4 & 60.9 & 34.6 & 4.5 & $<0.001$ \\
\hline Prefer a pharmacy near the GP's surgery & 79.9 & 15.4 & 4.7 & 72.8 & 20.4 & 6.9 & 0.023 \\
\hline Need a pharmacy open in the evening & 74.6 & 21.4 & 4.0 & 42.4 & 45.7 & 11.9 & $<0.001$ \\
\hline Need a pharmacy open on Saturdays & 76.7 & 20.6 & 2.7 & 63.8 & 29.4 & 6.8 & $<0.001$ \\
\hline Need a pharmacy open on Sundays & 62.7 & 27.0 & 10.2 & 29.1 & 49.3 & 21.7 & $<0.001$ \\
\hline \multicolumn{8}{|l|}{ Pharmacy staff } \\
\hline I/patients recognize the pharmacist & 59.1 & 34.6 & 6.4 & 91.8 & 7.0 & 1.2 & $<0.001$ \\
\hline The pharmacist knows me/patients & 55.6 & 36.3 & 8.1 & 85.5 & 12.7 & 1.8 & $<0.001$ \\
\hline Pharmacy staff know me/patients & 45.9 & 44.8 & 8.4 & 81.2 & 14.4 & 1.5 & 0.013 \\
\hline Pharmacist is same gender as me/patient & 21.6 & 59.7 & 18.8 & 12.9 & 62.5 & 24.6 & 0.001 \\
\hline Pharmacist appears approachable & 87.4 & 11.3 & 1.3 & 96.7 & 3.6 & 0.3 & $<0.001$ \\
\hline Pharmacist has previously given me/patient time & 76.5 & 21.0 & 2.5 & 93.3 & 5.8 & 0.9 & $<0.001$ \\
\hline Staff have previously been able to meet my/patient's needs & 83.1 & 14.8 & 2.0 & 97.3 & 2.4 & 0.3 & $<0.001$ \\
\hline \multicolumn{8}{|l|}{ Pharmacy practices } \\
\hline Prefer pharmacy staff make it easy to speak to the pharmacist & 81.6 & 16.6 & 1.8 & 88.5 & 10.0 & 1.5 & 0.029 \\
\hline Prefer not to speak when others can overhear & 59.1 & 35.1 & 5.8 & 71.2 & 23.0 & 5.8 & $<0.001$ \\
\hline Prefer to talk to a pharmacist in a private room & 42.0 & 47.9 & 10.1 & 61.0 & 33.5 & 5.5 & $<0.001$ \\
\hline Prefer pharmacy with good working relationship with GP's surgery & 73.3 & 22.3 & 4.4 & 52.9 & 36.9 & 10.3 & $<0.001$ \\
\hline $\begin{array}{l}\text { Prefer not to share reasons for asking to speak to the pharmacist } \\
\text { with pharmacy staff }\end{array}$ & 48.5 & 39.0 & 12.5 & 43.3 & 46.1 & 10.6 & 0.075 \\
\hline Prefer not to interrupt a pharmacist who is busy in the dispensary & 84.0 & 9.8 & 6.3 & 28.0 & 37.7 & 34.3 & $<0.001$ \\
\hline Trust pharmacist to keep personal information confidential & 94.8 & 4.5 & 0.5 & 90.9 & 7.6 & 1.5 & 0.039 \\
\hline Trust the pharmacy staff to keep personal information confidential & 90.1 & 7.6 & 2.3 & 87.0 & 11.8 & 1.2 & 0.031 \\
\hline
\end{tabular}

Abbreviation: GP, general practitioner. 
preference not to interrupt a pharmacist who is busy in the dispensary (84\%).

More regular medicine or frequent pharmacy users indicated preferences for using the same pharmacy, a pharmacy where pharmacists and staff know them, for privacy and for good working relationships with their doctor, compared to those not using regular medicines or pharmacies frequently (Table 3).

Statistically significant differences in expressed preferences and perceived needs for different pharmacy attributes were also found in relation to age, work status, and gender, but not for ethnicity, deprivation status, or educational status. Respondents aged 65 years or older were significantly more likely to prefer to use the same pharmacy than those aged 35-64 years and 34 years or younger $(76 \%, 66.1 \%$, $59.6 \%$, respectively), and one where they recognize the pharmacist $(72.8 \%, 56.5 \%, 53.2 \%)$ and the staff know them $(58.1 \%, 40.5 \%, 47.5 \%)$. Preferences were reversed in relation to using pharmacy in a supermarket, with those aged 34 years or younger having the highest preference compared to those aged 35-64 years and 65 years or older (28.9\%, 19\%, 13.4\%, respectively). Respondents aged 18-34 and 35-64 years were more likely to prefer a pharmacy near to where they work $(69.9 \%$ and $62.2 \%$ respectively) than those aged 65 years or over $(29.8 \%)$ and also one open in the evenings ( $77.8 \%$ and $77.6 \%$ respectively, compared to $63.6 \%$ for those aged 65 years or over). Fewer respondents who were working full time preferred to use the same pharmacy each time than those working part time, retired, or not working (57.6\% vs $73.4 \%$ ); those in work were more likely to prefer a pharmacy near to where they work $(68.8 \%$ vs $40.5 \%)$ and open in the evenings $(78.75 \%$ vs $68.1 \%)$.

Proportionally more female than male respondents indicated a preference for a pharmacy where they recognize the pharmacist ( $65.3 \%$ vs $52.6 \%)$, for a pharmacist the same gender as them $(28.4 \%$ vs $13.6 \%)$, not to speak when others can overhear ( $67.6 \%$ vs $47.9 \%$ ), not to share their reasons for asking to speak to the pharmacist with staff (54.8\% vs $41.4 \%$ ), for staff to make it easy to speak to the pharmacist

Table 3 Differences in public preferences for aspects of pharmacy characteristics and practices dependent on the use of medicines and pharmacies

\begin{tabular}{|c|c|c|c|c|}
\hline \multirow[t]{3}{*}{ Pharmacy characteristic/practice } & \multicolumn{4}{|c|}{ Proportion (\%) agreeing with preference } \\
\hline & \multicolumn{2}{|c|}{ Regular medicines use } & \multicolumn{2}{|l|}{ Pharmacy use } \\
\hline & $\begin{array}{l}\text { Yes } \\
(\max n=60 I)\end{array}$ & $\begin{array}{l}\text { No } \\
(\max n=395)\end{array}$ & $\begin{array}{l}\text { Frequent } \\
(\max n=504)\end{array}$ & $\begin{array}{l}\text { Infrequent } \\
(\max n=487)\end{array}$ \\
\hline \multicolumn{5}{|l|}{ Pharmacy characteristics } \\
\hline Prefer to use same pharmacy every time & 79.0 & $47.6 *$ & 79.8 & $52.8 *$ \\
\hline Prefer pharmacy owned by a large company & 36.1 & $28.9 *$ & 37.2 & 29.2 \\
\hline Prefer pharmacy owned by a pharmacist working there & 30.6 & $21.0 *$ & 32.8 & $20.7^{*}$ \\
\hline Do not prefer a pharmacy in a supermarket & 47.9 & $25.6 *$ & 44.7 & $33.3^{*}$ \\
\hline Prefer a pharmacy near where I live & 89.2 & $76.2^{*}$ & 89.5 & $78.3^{*}$ \\
\hline Prefer a pharmacy near the GP's surgery & 88.7 & $66.5^{*}$ & 88.3 & $71.1 *$ \\
\hline Prefer a pharmacy open in the evening & 77.9 & $69.5^{*}$ & 77.9 & 71.1 \\
\hline \multicolumn{5}{|l|}{ Pharmacy staff } \\
\hline Prefer a pharmacy where I recognize the pharmacist & 73.0 & $38.0 *$ & 72.5 & $45.3^{*}$ \\
\hline Prefer a pharmacy where pharmacist knows me & 68.6 & $35.9 *$ & 69.4 & $41.2^{*}$ \\
\hline Prefer a pharmacy where staff know me & 53.0 & $36.1 *$ & 55.2 & $36.9 *$ \\
\hline Prefer a pharmacy where pharmacist appears approachable & 92.0 & $80.6^{*}$ & 92.5 & $82.3^{*}$ \\
\hline Prefer a pharmacist who has previously given me time & 84.3 & $64.5^{*}$ & 84.4 & $68.2^{*}$ \\
\hline Staff have previously been able to meet my needs & 89.0 & $74.5^{*}$ & 89.3 & $76.9^{*}$ \\
\hline \multicolumn{5}{|l|}{ Pharmacy practices } \\
\hline Prefer pharmacy staff make it easy to speak to the pharmacist & 84.8 & 77.3 & 87.1 & $76.2^{*}$ \\
\hline Prefer not to speak when others can overhear & 63.9 & $52.0 *$ & 65.0 & $53.2^{*}$ \\
\hline Prefer a pharmacy where I can talk in a private room & 47.9 & $32.7^{*}$ & 51.3 & $32.0 *$ \\
\hline Prefer pharmacy with good working relationship with GP's surgery & 80.5 & $62.5^{*}$ & 84.0 & $62.3 *$ \\
\hline Prefer not to interrupt a pharmacist who is busy in dispensary & 87.6 & $78.3^{*}$ & 87.9 & $79.8^{*}$ \\
\hline Trust pharmacist to keep personal information confidential & 97.5 & $91.1 *$ & 97.6 & $92.1^{*}$ \\
\hline Trust staff to keep personal information confidential & 93.1 & $85.5^{*}$ & 92.7 & 87.4 \\
\hline
\end{tabular}

Note: $* P<0.001$, chi-squared test.

Abbreviations: GP, general practitioner; max, maximum. 
$(86.9 \%$ vs $76.1 \%)$, and to have a conversation in a private room $(48.2 \%$ vs $35 \%)$.

\section{Differences between pharmacist perceptions and public views}

The views of pharmacists differed significantly from views expressed by the public (Table 2), but were more in line with the preferences of regular medicine users and frequent pharmacy users. Pharmacists generally overestimated people's preferences for using the same pharmacy, independent ownership, personal knowledge of the pharmacist, approachability, and previous good service. Conversely, public desire for long opening hours and for a pharmacy which had a good relationship with their doctor's surgery was higher than pharmacists believed and pharmacists did not anticipate that the public prefer not to interrupt a pharmacist who is busy in the dispensary.

\section{Further reasons for choosing pharmacies}

A total of 56 pharmacists (16.4\%) made additional suggestions why people may choose a particular pharmacy (Table 4). These covered efficiency and reliability of services (eleven), previous good experiences (ten) and additional service provision (ten), accessibility (five), cleanliness and staff smartness (four), good communication skills (three), and staff continuity (three). Comparatively, few members of the public $(63 ; 6.3 \%)$ gave additional reasons for choosing a pharmacy. The most commonly cited reasons covered parking and disabled access (twelve), location (ten), efficiency (eleven), and the pharmacy environment (seven).

\section{Preferences for promotional methods for medicine-related services}

Overall views of both the public and pharmacists on the promotional methods viewed as most effective in encouraging the uptake of services are shown in Figure 1. Those judged most effective all involved direct recommendation, by general practitioners (GPs) or other health professionals, pharmacists and their staff, or friends and family. However, with the exception of doctor recommendation, significantly more pharmacists than members of the public believed that all potential promotional methods may be effective in encouraging the uptake of services. Among the public, factors with most influence on positive views toward promotional methods were: female gender, frequent pharmacy use, and experience of one of the services (Table 5). Age and educational level influenced only preferences toward health care websites and email. Personal email was preferred by slightly more of non-white ethnicity. There were no differences in preferences among subgroups for other forms of promotion: TV, radio, local newspaper, or leaflets in public places. Binary logistic regression, including gender, age

Table 4 Views expressed by the public and pharmacists on attributes perceived as important in choosing a pharmacy and promotion of services

\begin{tabular}{|c|c|c|}
\hline $\begin{array}{l}\text { Respondent } \\
\text { group }\end{array}$ & Comment & Respondent descriptor \\
\hline \multicolumn{3}{|c|}{ Views on attributes important for choosing a particular pharmacy } \\
\hline $\begin{array}{l}\text { Public } \\
\text { views }\end{array}$ & $\begin{array}{l}\text { "How good my relationship is with the pharmacist and if they're efficient having my medicines } \\
\text { ready to collect on time." } \\
\text { "Its appearance, it needs to be neat and tidy, not too busy as well." }\end{array}$ & $\begin{array}{l}\text { White female, aged } 45-54 \text { years, } \\
\text { in full-time work } \\
\text { Asian female student, } \\
\text { aged } 24 \text { years or younger }\end{array}$ \\
\hline $\begin{array}{l}\text { Pharmacist } \\
\text { views }\end{array}$ & $\begin{array}{l}\text { "Patients visit the pharmacist who has previously given 'good' advice even if they do not use } \\
\text { the pharmacy regularly." } \\
\text { "Communication skills of pharmacist. If patients can communicate fully with the pharmacist } \\
\text { with no difficulty, and they feel listened to, they will prefer to return." }\end{array}$ & $\begin{array}{l}\text { Female second pharmacist, } \\
\text { independent pharmacy } \\
\text { Male second pharmacist, large } \\
\text { multiple }\end{array}$ \\
\hline \multicolumn{3}{|c|}{ Views on promotion of medicine-related services } \\
\hline $\begin{array}{l}\text { Public } \\
\text { views }\end{array}$ & $\begin{array}{l}\text { "GPs should promote what pharmacists can do." } \\
\text { "If doctor says it, it becomes like a marketing deal - so they shouldn't get involved." } \\
\text { "Informing people when in pharmacy. People can't be bothered to read leaflets." }\end{array}$ & $\begin{array}{l}\text { Black female, aged } 65 \text { years or older } \\
\text { Asian female, aged } 45-54 \text { years } \\
\text { White male, aged } 35-54 \text { years }\end{array}$ \\
\hline \multirow[t]{2}{*}{$\begin{array}{l}\text { Pharmacist } \\
\text { views }\end{array}$} & $\begin{array}{l}\text { "Pharmacists try but struggle to promote these services. Patients view us as businesses and } \\
\text { are suspicious, even if we tell them the NHS are behind it. MURs - If doctors and the NHS } \\
\text { advertised and referred patients to tell them it was expected they should have this review, and } \\
\text { that the GP wanted them to, then the reviews would be much more useful and less rushed." }\end{array}$ & Female manager, large multiple \\
\hline & $\begin{array}{l}\text { "I believe services should be advertised in the pharmacy and it should be up to the patient } \\
\text { to decide if he wants them, I don't like the hard sell that we have to approach patients to get } \\
\text { them into the consultation room." }\end{array}$ & Female locum, small chain \\
\hline
\end{tabular}

Abbreviations: GP, general practitioner; MUR, medicines use review; NHS, National Health Service [England]. 


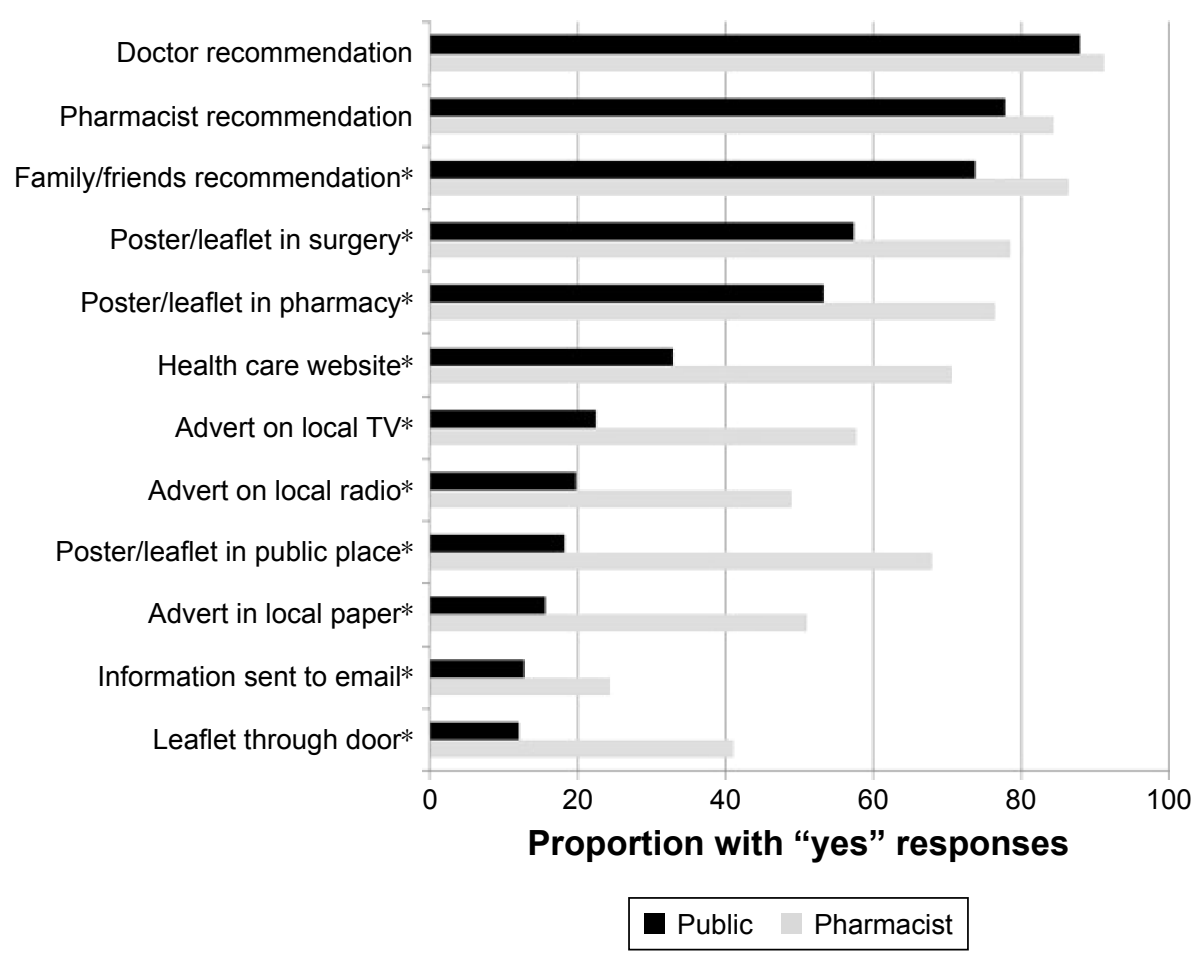

Figure I Proportions of public and pharmacist respondents indicating agreement that promotional methods are effective in encouraging service uptake. Note: $* P<0.001$, chi-squared test.

group, ethnicity, education, frequency of pharmacy use, and experience of services found that gender, age group, and frequency of pharmacy use were the key factors influencing promotional methods (Table 6).

Additional comments on promotional methods were added by $30(3 \%)$ members of the public, of which only ten suggested alternative methods: social media (six), apps for smartphones (two), and text messages (two). Two advocated GP recommendation, while one felt it was inappropriate (Table 4), others suggested pharmacists needed a proactive approach. A total of $53(13.6 \%)$ pharmacists commented on promotion including: involving other health professionals (eleven) or national representative bodies (two), relationships with GPs and their involvement in promotion (ten), and difficulties in encouraging patients to take up services (six).

\section{Discussion}

\section{Main findings}

The perceptions of community pharmacists in this survey about what attributes of pharmacies, staff, and practices they believe are important to their customers differed considerably from the views expressed by the general public. There were also significant differences in the views of pharmacists and the public on how effective different promotional methods for medicine-related services may be. Pharmacists recognize that pharmacy location is important, but their perceptions of the need for evening and weekend opening hours fell below those of the public, which were high in all age groups. Convenience is clearly an important factor influencing those who prefer supermarkets, and pharmacies near to place of work, particularly among those of working age, which may have been underestimated by pharmacist respondents. Pharmacists appear to have overestimated public preferences for pharmacies where customers are known and have received previous good service, but their views on this were similar to those of frequent pharmacy users, suggesting that, once established, relationships are important. Both pharmacists and the public viewed being approachable as important, but the perception among the public that they prefer not to interrupt a pharmacist who is busy in the dispensary suggests that this aspect of approachability may need to be considered. The desire for privacy was estimated to be higher by pharmacists than expressed by the public, while a pharmacy which has a good relationship with GPs was higher among the public preferences. Trust in maintaining confidentiality was high, which was recognized by pharmacists.

Direct recommendation was seen as the most effective overall approach for promoting pharmacy services by both pharmacists and the public, but pharmacists had higher expectations of the effectiveness of other methods, 


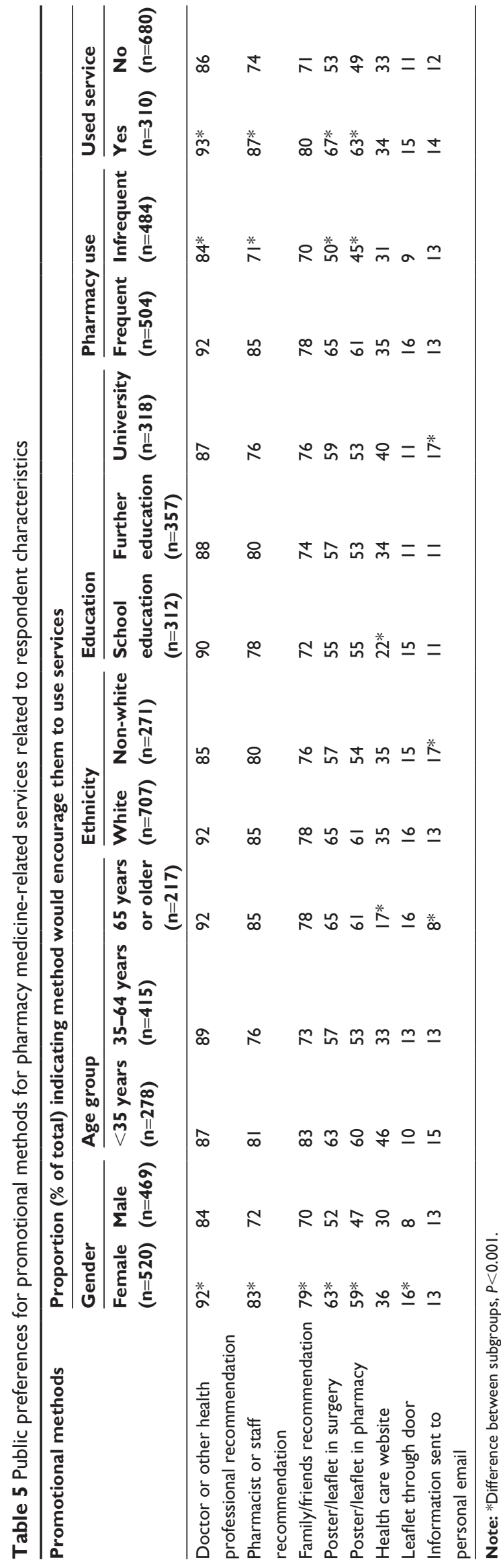

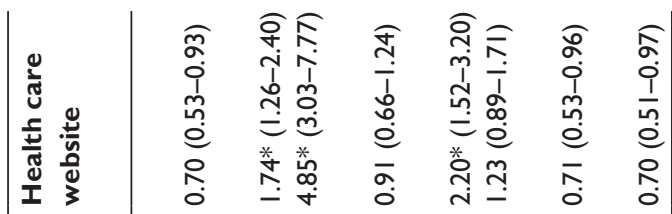

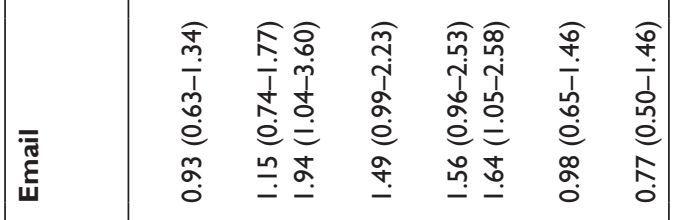

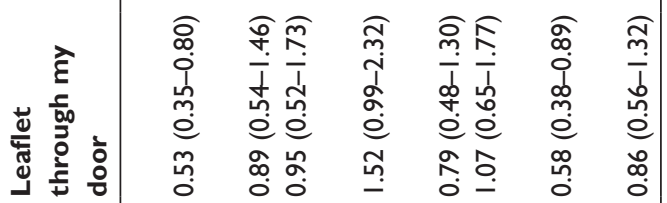

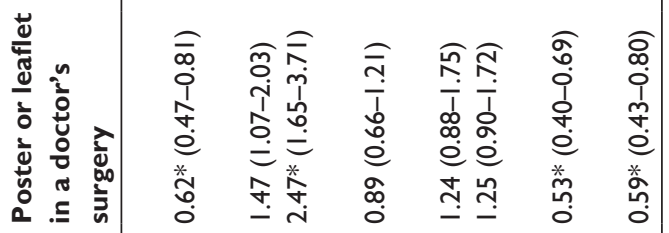

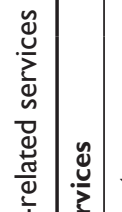

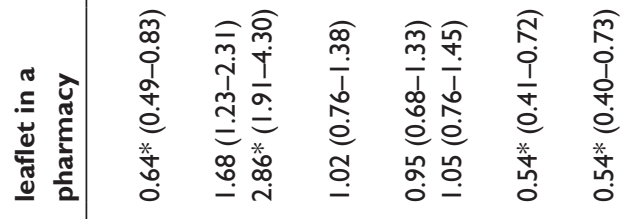

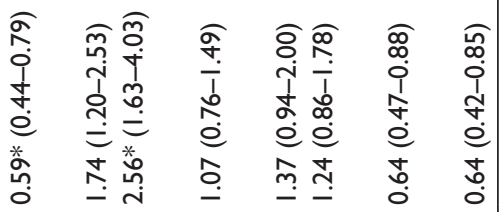

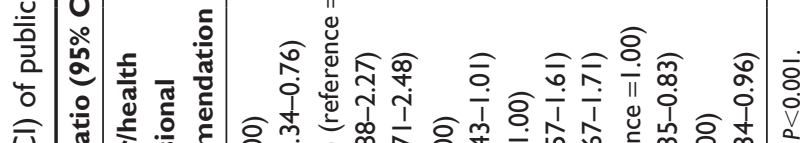

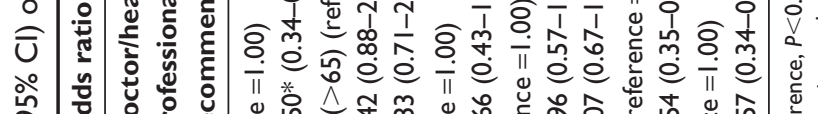

苍 을

$\frac{5}{0}$
0
0
$\frac{0}{0}$
$\frac{0}{6}$

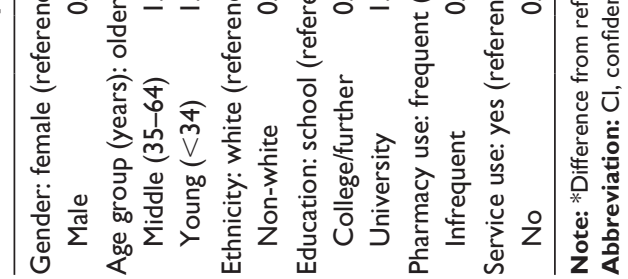


in particular, posters/leaflets (wherever located), and mass media advertising, than was expressed by the public. Both previous experience of services and frequent pharmacy use influenced views on promotional methods; hence, the emphasis on direct recommendation is relevant. Not surprisingly, technological methods such as health websites and email appealed more to younger people, those of higher educational level and those in work.

\section{Strengths and limitations}

This study is the first to compare the views of pharmacists and the public in England on what factors are important in choosing a particular pharmacy and on promoting pharmacy services related to medicines. Findings from focus groups were used to generate items for the questionnaires, which, although containing primarily closed questions, did include open-ended questions seeking additional views. The two surveys were complementary and covered large geographical areas of England with some overlap; both achieved large sample sizes and reasonable $(>40 \%)$ response rates. The public survey achieved a representative mix of age, gender, and deprivation of the Kent population, and the findings on pharmacy use compare well with other large surveys. ${ }^{9-11}$ It deliberately set out to include people who were not frequent pharmacy users or regular medicine users, although the majority were, which reflects national usage data. ${ }^{9-11}$ Unlike many other studies, it did not focus on users of pharmacies or of medicine-related services. ${ }^{13,18,19}$ The pharmacist responders were representative of the community pharmacies in terms of ownership and delivery of national commissioned medicine-related services.

The public survey used a face-to-face method, which could result in more positive responses, due to obsequiousness bias, which was compared to a self-completed pharmacist survey. However, street surveys are a cost-effective method of obtaining public views ${ }^{23}$ and can avoid misunderstanding of questions, while face-to-face methods involving pharmacists are less feasible due to time and budgetary constraints.

\section{Implications for practice}

Pharmacists in many countries who provide a range of services to support and improve medicines use, in addition to standard advice giving, need to appreciate the desirability of different pharmacy attributes to potential users of these services. In Australia, consumers want pharmacies that provide patient-centered care, with convenience, prices and pharmacies that meet their expectations being additional factors. ${ }^{6}$ Australian pharmacists recognized the consumers' desire for patient-centered care, accessibility, and continuity of care but did not realize their desire for information. ${ }^{3}$ This study suggests that English pharmacists' perceptions also do not fully align with those of potential service users. Pharmacists may not recognize that convenience, including opening times, is a priority for most people, perhaps more than pharmacy ownership, although earlier work has shown that English consumers view pharmacy location as important. ${ }^{11}$ Loyalty to one pharmacy is mostly important for regular medicines or pharmacy users, but does vary depending on patient characteristics, as has been shown in other studies. ${ }^{24,25}$ Relationships, pharmacy atmosphere, and quality of previous experiences are also obviously key factors influencing repeat patronage. ${ }^{26}$ However, in this study, being known to the pharmacist and their staff and previous good service were judged as important by fewer public than pharmacist respondents.

Other key areas perceived as important by more members of the public than pharmacists were the pharmacy's relationship with doctors and actual accessibility of the pharmacist. For medicine-related services such as MUR or NMS, good relationships with GPs are essential, but this study indicates that these should also be harnessed to help promote these services. Relationships between pharmacists and GPs in England have been suggested to vary from isolation, through communication to full collaboration. ${ }^{27}$ While proximity and location are obviously key factors influencing the opportunities for collaborative relationships, the need for mutual professional respect cannot be overestimated. Without this, the possibility that GPs will promote pharmacy services, perceived by both groups as the most effective method, appears remote. The Australian model of HMR, in contrast, requires referral from a GP but has suffered from low uptake. ${ }^{14}$ Busyness of pharmacists and pharmacies has been found as a potential barrier to uptake of services in earlier studies. ${ }^{28-30}$ Word of mouth is obviously a key promotional method highlighted by this study and advocated elsewhere, ${ }^{18}$ which pharmacists and their staff need to use effectively themselves, particularly as it costs nothing and requires no permission from others or external cooperation with local service commissioners. Personal recommendations could, for example, be encouraged by the use of "pass-it-on" cards, given to people who have received a service for distribution to others who have not. Findings of this study suggest that posters/leaflets and mass media methods are all potentially less effective, but other studies indicate these methods influence some people. ${ }^{18,31-33}$ Mass media methods have been 
found in users of one US pharmacy to increase awareness but not use of services. ${ }^{26}$ Whatever method is used, regular promotional messages are likely to be needed to increase the uptake of these important services for the optimization of medicines, and learning from the potential consumers of these services is essential. ${ }^{34}$

\section{Conclusion}

Pharmacists and pharmacy owners should consider the factors seen as important by the public in selecting pharmacies when they require a medicine-related service, where possible, ensuring good relationships with GPs, to enable them to maximize opportunities for using the promotional methods judged to be most effective in encouraging the uptake of these services. Staff must be approachable and enable customers to speak to pharmacists, while ensuring that perceptions of pharmacist busyness do not deter them from seeking to do so.

\section{Acknowledgments}

The authors are grateful to the undergraduate students who assisted with data collection and to the pharmacists and members of the public who responded to the surveys.

\section{Disclosure}

The authors report no conflicts of interest in this work.

\section{References}

1. Puspatasari HP, Aslani P, Krass I. Pharmacists' and consumers' viewpoints on counselling on prescription medicines in Australian community pharmacies. Int J Pharm Pract. 2010;18:202-208.

2. McMillan S, Kelly F, Sav A, King MA, Whitty JA, Wheeler AJ. Australian community pharmacy services: a survey of what people with chronic conditions and their carers use versus what they consider important. $B M J$ Open. 2014;4(12): 0006587.

3. McMillan S, Kelly F, Sav A, et al. Consumers and carers versus pharmacy staff: do their priorities for Australian pharmacy services align? Patient. 2015;8(5):411-422.

4. Law AV, Okamoto MP, Brock K. Perceptions of Medicare Part D enrollees about pharmacists and their role as providers of medication therapy management. J Am Pharm Assoc. 2008;48(5):648-653.

5. Doucette WR, Witry MJ, Alkhateeb F, Farris KB, Urmie JM. Attitudes of Medicare beneficiaries toward pharmacist provided medication therapy management services as part of the Medicare Part D benefit. J Am Pharm Assoc. 2007;47:758-762.

6. McMillan S, Sav A, Kelly F, King MA, Whitty JA, Wheeler AJ. How to attract them and keep them: the pharmacy attributes that matter to Australian residents with chronic conditions. Int J Pharm Pract. 2014;22(4):238-245.

7. Whitty JA, Kendall E, Sav A, et al. Preferences for the delivery of community pharmacy services to help manage chronic conditions. Res Social Admin Pharm. 2015;11(2):197-215.

8. McMillan S, Sav A, Kelly F, King MA, Whitty JA, Wheeler AJ. Consumer and carer views of Australian community pharmacy practice: awareness, experiences and expectations. J Pharm Health Serv Res. 2014;5:29-36.
9. Boardman H, Lewis M, Croft P, Trinder P, Rajaratnam G. Use of community pharmacies: a population-based survey. J Pub Health. 2005;27:254-262.

10. COI on behalf of Department of health. Community Pharmacy UseQuantitative and Qualitative Research: Market Research Report. London: Continental Research. Available from: http://webarchive. nationalarchives.gov.uk/20130107105354/http://www.dh.gov.uk/ prod_consum_dh/groups/dh_digitalassets/@dh/@en/documents/ digitalasset/dh_083870.pdf. Accessed May 16, 2016.

11. Ipsos MORI. Public Perceptions of Pharmacies: The General Pharmaceutical Council; 2014. Available from: http://www. pharmacyregulation.org/sites/default/files/gphc_public_perceptions_ report_-_final.pdf. Accessed May 16, 2016.

12. Corlett SA, Dodds LJ, Rodgers RM. As pharmacists expand their clinical roles do the general public recognise what they can offer? Pharmacoepidemiol Drug Saf. 2013;22(6):672-673.

13. Elliott R, Boyd M, Waring J, et al. Understanding and appraising the New Medicines Service in the NHS in England (029/0124). Available from: http://www.nottingham.ac.uk/ pazmjb/nms/downloads/report/ index.html\#2/z. Accessed October 2, 2015. [Archived by WebCite ${ }^{\circledR}$ at http://www.webcitation.org/6bydND1cL]

14. Carter SR, Moles R, White L, Chen TF. Patients' willingness to use a pharmacist-provided medication management service: the influence of outcome expectancies and communication efficacy. Res Social Admin Pharm. 2012;8:487-498.

15. White L, Kinner C, Carter S. Consumer perspectives of the Australian home medicines review program: benefits and barriers. Res Social Admin Pharm. 2012;8(1):4-16.

16. Smith J, Picton C, Dayan M. Now More than Ever: Why Pharmacy Needs To Act; 2014. Available from: http://www.nuffieldtrust.org.uk/ sites/files/nuffield/publication/now_more_than_ever.pdf. Accessed May 16, 2016.

17. Van den Berg M, Donyai P. How was patient empowerment portrayed in information leaflets describing the community pharmacy medicines use review service in the UK? Patient Educ Couns. 2010;80(2): 274-276.

18. Lindstrom NSR, Casper KA, Green TR, Pedersen CA. Designing pharmacy services based on grocery store patron preferences. $J$ Am Pharm Assoc. 2007;47(5):605.

19. Doucette W, McDonough RP. Beyond the 4Ps: using relationship marketing to build value and demand for pharmacy services. J Am Pharm Assoc. 2002;42:183-192.

20. Huet AL, Frail CK, Lake LM, Snyder ME. Impact of passive and active promotional strategies on patient acceptance of medication therapy management services. J Am Pharm Assoc. 2015;55(2):178-181.

21. Saramunee K, Krska J, Mackridge AJ, Richards J, Suttajit S, Philips-Howard P. General public views on pharmacy public health services: current situation and opportunities in the future. Pub Health. 2015; 129:705-715.

22. Rodgers RM, Gammie SM, Loo RL, Corlett SA, Krska J. Comparison of pharmacist and public views and experiences of community pharmacy medicines-related services in England. Patient Prefer Adherence. 2016;10:1749-1758.

23. Saramunee K, Krska J, Mackridge AJ, Richards J, Suttajit S, Philips-Howard P. Methodological and economic evaluations of eight survey modes applied to health service research. J Pharm Health Serv Res. 2016;7(1):43-52.

24. Wazaify M, Shields E, Hughes CM, McElnay JC. Societal perspectives on over-the-counter (OTC) medicines. Fam Pract. 2005;22(2): 170-176.

25. Peterson GM, Jackson SL, Hughes JD, Fitzmaurice KD, Murphy LE. Public perceptions of the role of Australian pharmacists in cardiovascular disease. J Clin Pharm Thera. 2010;35(6):671-677.

26. Patterson BJ, Doucette WR, Urmie JM, McDonough RP. Exploring relationships among pharmacy service use, patronage motives and patient satisfaction. J Am Pharm Assoc. 2013;53(4):382-389. 
27. Bradley F, Ashcroft DM, Noyce P. Integration and differentiation: a conceptual model of general practitioner and community pharmacist collaboration. Res Social Adm Pharm. 2012;8(1):36-46.

28. Krska J, Morecroft CW. Views of the general public on the role of pharmacy in public health. J Pharm Health Serv Res. 2010;1(1):33-38.

29. Saramunee K, Krska J, Mackridge AJ, Richards J, Suttajit S, Philips-Howard P. How to enhance the uptake of public health services in community pharmacy? A qualitative study. Res Soc Admin Pharm. 2014; 10(2):272-284.

30. Eades CE, Ferguson JS, O'Carroll RE. Public health in community pharmacy: a systematic review of community pharmacist and consumer views. BMC Public Health. 2011;11:1-45.

31. Garcia GM, Snyder ME, McGrath SH, Smith RB, McGivney MS. Generating demand for pharmacist-provided medication therapy management: identifying patient-preferred marketing strategies. J Am Pharm Assoc. 2009;49(5):611-616.
32. Taylor JC, Krska J, Mackridge AJ. A community pharmacy-based cardiovascular screening service: views of service users and the public. Int J Pharm Pract. 2012;20(5):277-284.

33. Krska J, Mackridge AJ. Development and testing of a feasible and desirable community pharmacy-based identification and brief advice service for alcohol. Pub Health. 2014;128:309-316.

34. Isetts BJ, Schommer JC, Westberg SM, Johnson JK, Froiland N, Hedlund JM. Evaluation of a consumer-generated marketing plan for medication therapy management services. Innov Pharm. 2012; 3(1):Article66

\section{Publish your work in this journal}

Patient Preference and Adherence is an international, peer-reviewed, open access journal that focuses on the growing importance of patient preference and adherence throughout the therapeutic continuum. Patient satisfaction, acceptability, quality of life, compliance, persistence and their role in developing new therapeutic modalities and compounds to optimize clinical outcomes for existing disease states are major areas of interest for the journal. This journal has been accepted for indexing on PubMed Central. The manuscript management system is completely online and includes a very quick and fair peer-review system, which is all easy to use. Visit http://www. dovepress.com/testimonials.php to read real quotes from published authors.

Submit your manuscript here: http://www.dovepress.com/patient-preference-and-adherence-journal 